\title{
ECOINOVAÇÃO EM UMA PEQUENA EMPRESA DE RECICLAGENS DA CIDADE DE MANAUS
}

\section{Moisés Andrade Coelho}

Mestre em Engenharia de Produção pela Universidade Federal do Rio de Janeiro - UFRJ moises.acoelho@gmail.com (Brasil)

\section{RESUMO}

O presente artigo possui como objetivo uma análise para a caracterização do processo de ecoinovação realizado pela empresa Ômega. No tocante a metodologia, este trabalho é considerado uma pesquisa qualitativa e descritiva que utiliza como procedimento metodológico o estudo de caso. Como técnicas de pesquisa foram utilizadas a documentação indireta (pesquisa documental), a observação direta intensiva (observação e entrevista estruturada) e a observação direta extensiva (formulário de ecoinovação). Nos resultados são apresentados o contexto da empresa e do processo produtivo, os resultados do formulário de ecoinovação e as principais ecoinovações (produto, processo e social) adotadas pela empresa. As considerações finais apontam para a adequação entre as inovações em produtos e processos desenvolvidos pela empresa e a literatura apresentada. Com isso, a empresa Ômega pode ser considera como sendo ecoinovadora estratégica. A relevância do estudo reside na apresentação de um formulário para se avaliar atividades ecoinovadoras dentro das empresas e pela validação entre as ecoinovações observadas na empresa e a literatura existente.

Palavras-chaves: Inovação; Ecoinovação; Fibras de juta; Guaraná; Amazonas. 


\section{INTRODUÇÃO}

A vantagem competitiva está mudando paulatinamente em favor das empresas que mobilizam conhecimento e avanços tecnológicos na concepção de novidades em produtos/serviços e na forma como os produzem e lançam. $\mathrm{O}$ desenvolvimento de produto é uma capacidade importante devido às constantes mudanças do ambiente, bem como a inovação em processo é relevante na medida em que uma organização realiza algo que ninguém mais pode fazer ou fazendo melhor do que os outros (TIDD et al., 2008).

Durante anos adotou-se que a inovação em produto era desenvolvida tipicamente pelos fabricantes. Todavia, as fontes de inovações são variadas e em alguns campos os usuários participam do desenvolvimento de muitas inovações, enquanto em outros os fornecedores são as fontes de inovação, por exemplo. Sendo assim, a inovação poderá advir de uma série de relacionamentos envolvendo usuários, clientes e fornecedores e as variações nas fontes de inovações são causadas pelo grau de importância dado nas variações das expectativas dos potenciais inovadores na lucratividade relacionada à inovação (VON HIPPEL, 1998).

Nas últimas décadas a expansão do crescimento econômico tem sido acompanhada pelo crescimento do interesse ambiental global no que diz respeito às mudanças climáticas, segurança energética e aumento na escassez dos recursos. Em resposta, as indústrias tem, recentemente, demonstrado um maior interesse na produção sustentável e adotado iniciativas de responsabilidade social corporativa. Contudo, tais esforços estão longe de atender aos eminentes desafios para a manufatura sustentável. Além disso, eficientes aperfeiçoamentos em algumas regiões têm sido compensados pelo aumento do consumo em outras regiões (OECD, 2009a).

Analogamente, a recente crise econômica e as negociações para o combate as mudanças climáticas devem ser vistas como oportunidades para o ajuste em direção a uma economia verde. As melhorias incrementais não são suficientes com relação aos desafios climáticos que surgem em médio e longo prazo. Sendo assim, a indústria deve ser reestruturada e as tecnologias existentes precisam ser aplicadas de forma mais inovadora para realizar o crescimento verde. Em curto prazo, os pacotes de ajudas implantados poderão estimular investimentos em tecnologias e infraestruturas que ajudarão a inovação e possibilitarão as mudanças nas formas de produzir e consumir os bens e serviços no futuro (OECD, 2009b).

Nesse contexto, a manufatura sustentável ou ecoinovação está no coração dessas políticas e práticas industriais. Esses conceitos têm se tornado cada vez mais populares por meio dos 
formuladores de políticas e empresários mediante o encorajamento de soluções nos negócios e ideias empreendedoras para o combate às mudanças ambientais (OECD, 2009a). No caso da Amazônia, como sendo fonte de recursos naturais, minerais e hídricos, bem como gigantesco banco genético e da biodiversidade a ecoinovação, é uma alternativa para o crescimento econômico e a redução das desigualdades sociais históricas da região pelo desenvolvimento de produtos à base de insumos amazônicos.

Assim, o objetivo desta pesquisa consistiu em fazer uma análise do processo de ecoinovação realizado pela empresa Ômega, com vista a identificar os fatores internos e externos que influenciaram a busca e a decisão pela ecoinovação. A importância da pesquisa, internamente, reside na apresentação de um formulário que permite avaliar as atividades ecoinovadoras dentro de uma empresa, identificando lacunas relacionadas ao tema e possibilitando o desenvolvimento de estratégicas competitivas para as empresas por intermédio de ecoinovações. Externamente, o formulário poderá ser utilizado para estudos em nível macro, de um conjunto de empresas, com o intuito de apoiar futuras políticas públicas voltadas para o desenvolvimento sustentável de uma determinada região.

Este trabalho está estruturado em três tópicos com os seus respectivos conteúdos. O primeiro tópico apresenta a revisão da literatura contendo os conceitos de inovação, ecoinovação e finaliza com a apresentação das características do cultivo das fibras de Juta e guaraná no estado do Amazonas. O segundo tópico trabalha a metodologia e as técnicas de pesquisa utilizadas no estudo. Por fim, o terceiro tópico demonstra o estudo de caso na empresa Ômega que utiliza a ecoinovação como diferencial competitivo e conclui com as considerações finais destacando as principais descobertas realizadas na pesquisa e as referências.

\section{REVISÃO DA LITERATURA}

\subsection{Inovação}

Para Schumpeter (1961) a inovação está relacionada aos novos bens de consumo, aos novos métodos de produção ou transporte, aos novos mercados e às novas formas de organização; a inovação é o impulso que mantém em funcionamento a máquina do capitalismo. Segundo o Manual de Oslo (OECD, 2005, p. 55), inovação "é a implementação de um produto (bem ou serviço) novo ou significativamente melhorado, ou um processo, ou um novo método de marketing, ou um novo método organizacional nas práticas de negócios, na organização do local de trabalho ou nas relações externas".

Revista de Administração e Inovação, São Paulo, v.12, n.1, p.121-147, jan./mar. 2015. 
Em termos de grau de novidade, o Manual de Oslo adota três conceitos: "nova para a empresa", "nova para o mercado" e "nova para o mundo". O requisito mínimo para se considerar uma inovação é que a mudança introduzida tenha sido nova para a empresa. Mesmo que um método de produção, processamento ou um método organizacional já tenha sido implementado por outras empresas. Todavia, se ele é novo para a empresa (ou se é o caso de produtos e processos significativamente melhorados), então se trata de uma inovação para essa empresa. No que tange aos conceitos de "nova para o mercado" e "nova para o mundo", decorrem do fato de determinada inovação ter sido ou não implementada por outras empresas, ou de a empresa ter sido a pioneira no mercado ou na indústria ou no mundo a implementar tal inovação. Essas empresas podem ser consideradas condutoras do processo de inovação (OECD, 2005).

A noção de que existem diferentes tipos de inovação com diferentes efeitos competitivos tem sido um importante tema da literatura em inovação tecnológica. A inovação Radical e incremental são pontos extremos ao longo de ambas as dimensões. As radicais estabelecem um novo design dominante e, por isso, um novo conjunto de conceitos essenciais incorporados nos componentes que estão ligados em conjunto em uma nova arquitetura. As incrementais refinam e estendem um design estabelecido (HENDERSON \& CLARK, 1990).

Além dos tipos tradicionais de inovação, Christensen (1997) distingue entre dois tipos fundamentais: (1) a inovação de sustentação (sustaining), em que as continuas melhorias na funcionalidade dos produtos atuais estão voltadas para os clientes e mercados existentes e (2) a inovação disruptiva (disruptive), em que se fornece um conjunto de diferentes funções para atrair um provável segmento de mercado diferenciado, não atendido anteriormente.

A inovação não se restringe aos setores hi-tech, ela é equitativamente distribuída pelos diferentes setores não impedindo os setores tradicionais de serem inovadores (CASSIOLATO \& LASTRES, 2000). A inovação empresarial trata de um "novo valor" e não de "novas coisas", sendo assim, a inovação somente será relevante se criar valor para os clientes e, portanto, para a empresa. Dessa forma, criar novas coisas não é nem necessário ou suficiente para a inovação nos negócios. São os clientes que definem o valor de uma inovação e se pagarão por ela (SAWHNEY et al., 2006).

A inovação não é simplesmente ter a ideia, mas trabalhar para desenvolver e implementar esta ideia no mundo dos negócios, todavia existem vários graus de novidade diferentes tipos de inovação. Estes diferentes tipos de inovação necessitam de diferentes tipos de organização (GALBRAITH, 1999). 


\subsection{Ecoinovação}

A organização inovadora sustentável é uma resposta às pressões institucionais por uma organização que seja capaz de inovar com eficiência no que tange aos aspectos econômicos, mas com responsabilidade social e ambiental. A vantagem competitiva desse tipo de organização reside no desenvolvimento de produtos, serviços, processos e negócios, novos ou modificados, tendo como base as dimensões social, ambiental e econômica e possuindo duas características essenciais: é uma organização (1) inovadora e (2) orientada para a sustentabilidade (BARBIERI et al., 2010).

O termo ecoinovação surgiu com Fussler \& James (1996) no livro Driving Eco-innovation: A Breakthrough Discipline for Innovation and Sustainability. Insere-se no contexto em que a escolha da tecnologia adequada abrange vários aspectos relacionados ao ambiente. A ecoinovação pode ser entendida como a produção, assimilação ou exploração de um produto, processo de produção, serviços, gestão ou método de negócios que é novo para a organização (desenvolvido ou adotado) e onde os resultados, em todo ciclo de vida, geram uma redução dos riscos do ambiente, poluição e outros impactos negativos dos recursos utilizados (incluindo o uso da energia) comparado às alternativas relevantes. As alternativas relevantes podem ser a tecnologia utilizada em uma empresa ou uma tecnologia comum a um setor (KEMP \& PEARSON, 2008).

A ecoinovação não necessariamente envolve novos conhecimentos ou novas tecnologias e pode não originar no domínio ambiental. Por essa razão, o espectro das políticas de ecoinovação é muito amplo, suas medidas requerem um complexo conjunto de indicadores incluindo seus impactos ambientais. A coordenação e a estabilidade de jurisdições e instrumentos políticos são essenciais, aliado a um compreensivo documento de referência nacional poderão facilitar a coordenação e a consistência da melhoria, especialmente, se estiver baseado em informações consistentes. $\mathrm{O}$ design de políticas mais eficientes leva em conta o desenvolvimento de padrões de ecoinovações as quais geram oportunidades para o escopo da cooperação econômica e/ou competição (OECD, 2011).

Assim, mediante a definição geral aplicada à ecoinovação, o conceito se desdobra em dois significados com características distintas, a saber (OECD, 2009a):

1. Ecoinovação é uma inovação que resulta, no sentido estrito do conceito, em uma redução dos impactos ambientais, independente, se o efeito é pretendido ou não;

2. Ecoinovação não se limita a inovações em produtos, processos, métodos organizacionais e de marketing, mas também incluem inovações sociais e nas estruturas institucionais. A ecoinovação e os benefícios ambientais devem ir além do convencional limite da

Revista de Administração e Inovação, São Paulo, v.12, n.1, p.121-147, jan./mar. 2015. 
organização e do inovador e adentrar no amplo contexto social por meio das mudanças nas normas sociais, valores culturais e estruturas institucionais.

A ecoinovação se difere do conceito clássico de inovação por se relacionar com a redução dos encargos ambientais, ou seja, uma inovação que consiste em mudanças e melhorias no desempenho ambiental dentro de um contexto de ecologização de produtos, processos, estratégias de negócios, mercados, tecnologias e sistemas de inovação. Logo, a ecoinovação tem contribuição direta com a redução dos impactos ambientais de produtos e processos (MAÇANEIRO \& CUNHA, 2010).

Para Rennings (1998), a ecoinovação pode ser desenvolvida por empresas ou organizações sem fins lucrativos, podendo ser comercializadas ou não e sua natureza pode ser (1) tecnológica, (2) organizacional, (3) social ou (4) institucional. As ecoinovações tecnológicas podem ser divididas em tecnologias curativas e preventivas, onde as primeiras reparam os danos enquanto a segunda evita-os.

De maneira semelhante à Rennings, os autores Frondel et al. (2004) distinguem dois diferentes tipos de inovações ambientais: a primeira, denominada de produção mais limpa (cleaner production) e a segunda, denominada de tecnologias de fim de tubo (end-of-pipe Technologies). As produções mais limpas reduzem à utilização de recursos e/ou a poluição pela utilização de produtos e métodos mais limpos, enquanto as tecnologias de fim de tubo inibem a emissão de poluentes pela implementação de medidas complementares. Em estudo, Oltra et al. (2009) demonstram que as eco-patentes tendem a cobrir principalmente as tecnologias de fim de tubo, devido a serem mais facilmente identificáveis e possuindo nos impactos ambientais o principal objetivo para a motivação dessas invenções.

Do ponto de vista de Bleischwitz et al. (2009), os tipos de ecoinovação podem ser agrupados em três categorias principais:

1. Processo: uma inovação em processo é a implementação de uma nova ou significativamente melhorada produção ou método de entrega. Palavras-chave nessa área incluem produção mais limpa, zero emissões, perdas zero e eficiência de material;

2. Produto: ecoinovações em produto inclui um novo ou significativamente melhorado produto ou serviço, produzido de forma que todos os impactos ambientais são minimizados. Palavras-chave nessa área incluem os conceitos de eco-design, inovações tecnológicas sustentáveis, tecnologia ambiental e engenharia reversa;

3. Sistemas de inovação: esse tipo de inovação não apenas se refere a sistemas tecnológicos, mas também a tecnologias radicais e disruptivas que alteram as condições de mercado e todos os tipos de sistemas de mudanças, tais como, industrial, sociedade ou mudanças comportamentais. Palavras-chave nessa área incluem os conceitos de análise de ciclos de vida, produção e consumo sustentável e sistemas orientados pelos usuários.

Revista de Administração e Inovação, São Paulo, v.12, n.1, p.121-147, jan./mar. 2015. 
Em outra classificação, as ecoinovações podem ser categorizadas mediante a forma como as empresas introduzem inovações ambientais, a saber (KEMP \& PEARSON, 2008):

1. Ecoinovadores estratégicos: ativo em ecoequipamentos e serviços, desenvolver ecoinovações para vender a outras empresas;

2. Ecoadaptadores estratégicos: intencionalmente implementam ecoinovações, desenvolve internamente e/ou adquire de outras empresas;

3. Ecoinovadores passivos: inovações em processos, organizacional e produtos que resultam em benefícios ambientais, mas onde não existem estratégias específicas para inovar;

4. Não ecoinovadores: sem atividades para inovações sem pretensão ou intenção com benefícios ambientais.

\subsection{O cultivo das fibras de juta e do guaraná no estado do Amazonas}

A Amazônia passou, ao longo de sua história, por ciclos econômicos que motivaram as atividades a serem realizadas pelos seus habitantes em suas terras, bem como influenciaram de forma decisiva no desenvolvimento da área urbana das, que seriam mais tarde, principais cidades da região. A importância de dinamizar a economia da região é tomada como necessidade desde a Amazônia Provincial, quando as autoridades tentaram diversificar a produção agrícola com projetos que previam plantações de cacau, café, tabaco, guaraná, coleta de castanha e o látex da seringueira (BENTES \& ROLIM, 2005).

Muitos desses cultivos tiveram sua expansão pelas várzeas (terrenos encharcados, próximos à margem do Rio Amazonas), propiciando o povoamento nessas áreas consideradas muito férteis. Os terrenos de várzea são limitados pela terra firme e o pelo Rio Amazonas e, por sofrerem as subidas cíclicas do rio, contém grande quantidade dos ricos nutrientes, cálcio e fosfato, aproveitados nas plantações (BENTES \& ROLIM, 2005).

Com relação ao cultivo da Juta, a imigração japonesa contribuiu para a introdução da espécie na Amazônia. Nessa época, a economia regional era essencialmente extrativista e em estagnação resultantes da crise da borracha provocada pela biopirataria. A imigração japonesa introduziu o cultivo da juta nas várzeas amazônicas atingindo seu apogeu na década de 1960, participando de 1/3 do PIB do estado do Amazonas. Do mesmo modo, a cultura da pimenta do reino, no estado do Pará, chegou a participar com mais de 35\% do valor das exportações na década seguinte, 1970 (HOMMA, 2009).

Revista de Administração e Inovação, São Paulo, v.12, n.1, p.121-147, jan./mar. 2015. 
O sucesso da fibra de juta esteve diretamente ligado à ocorrência da II Guerra Mundial, que impossibilitou a importação da fibra de juta indiana pela inexistência de transporte marítimo. Outro fator determinante foi a existência de mão de obra (predominância de nordestinos) liberada com a crise da borracha, a qual passou a viver da caça e da pesca e da reduzida agricultura de subsistência ao longo das várzeas. O primeiro processo de agroindustrialização na Amazônia teve início com o beneficiamento da fibra de juta, com a instalação de fábricas de fiação e tecelagem em Castanhal, Belém, Santarém e Manaus. No período entre a crise da borracha (década de 1910) e a instalação da Zona Franca de Manaus (1967), a lavoura da juta foi que garantiu o sustento da economia do estado do Amazonas (HOMMA, 2009).

Os principais países produtores da juta são Índia (62\%), Bangladesh (35,7\%), Myanmar (1,7\%) e Nepal $(0,7 \%)$. Esses quatro países foram responsáveis por quase a totalidade da produção mundial em 2006. No caso do Brasil, o cultivo ocorre na região Norte, de forma pulverizada, em terras firmes do Pará e nas calhas dos rios da região Amazônica. De forma geral, os principais estados produtores são Amazonas (66,6\%), Pará (32,6\%) e Maranhão, com 0,3\% (SANTOS, 2007).

O estado do Amazonas possui suas terras agriculturáveis divididas em duas zonas agroecológicas: (1) a várzea, terras periodicamente inundadas que correspondem a apenas $9 \%$ das áreas agrícolas no Amazonas e a (2) terra firme, áreas que não são afetadas pela subida e descida das águas dos rios, correspondentes aos demais $91 \%$ das áreas agrícolas. Durante os meses de julho a novembro normalmente as áreas de várzea ficam expostas, o que permite que estas terras sejam utilizadas para a agricultura. As significativas diferenças de precipitação entre as estações chuvosa e seca sujeita o rio Amazonas a grandes flutuações em seu nível, que atinge um máximo em maio/junho (SOUZA, 2010).

A cadeia produtiva da juta e da malva no Amazonas é composta pelo seguimento dos fornecedores de sementes, a unidade de produção familiar, os atravessadores e as empresas processadoras de fibra. No Amazonas, o principal município produtor de juta e malva é Manacapuru, responsável por 58,5\% da produção do estado entre 1998 e 2002 (SOUZA, 2010). Entre os municípios do Amazonas que praticam a cultura da juta estão: Manacapuru, Beruri, Caapiranga, Iranduba, Manaquiri, Anamã, Parintins e Anori (IDAM, 2011).

No caso do guaraná, o Brasil é o único produtor, em termos comerciais, no mundo. No Amazonas, o guaranazeiro é uma cultura plantada tanto por grandes como por pequenos produtores. Atualmente, quase a totalidade da produção do guaraná é consumida no mercado interno. Estima-se que da demanda nacional de sementes de guaraná, pelo menos $70 \%$ seja absorvida pelos fabricantes de 
refrigerantes, enquanto o restante é comercializado na forma de xarope, bastão, pó, extrato e outras formas (EMBRAPA, 2005).

O guaraná tem sua origem Amazônica e, especialmente, no estado do Amazonas. Todavia, a concentração espacial da sua produção não impediu que fosse transferido dessa região para a Bahia, atualmente o maior e mais produtivo produtor do Brasil. No que tange à agroindustrialização do guaraná, os produtos finais de maior difusão e aceitação pelos mercados brasileiros e estrangeiros são os refrigerantes gaseificados à base do guaraná. Contudo, a transformação industrial do guaraná em xarope, bastão, artesanato e, principalmente, em pó abre amplas perspectivas mercadológica para investidores (SUFRAMA, 2003).

Dentro do estado do Amazonas, só o município de Maués, a 356 km de Manaus, produziu cerca de 200 toneladas em 2001, concentrando 37\% da produção estadual do guaraná neste mesmo ano. Essa produção de Maués está distribuída por, aproximadamente, 2.600 produtores, em 2.427 ha de área plantada (SUFRAMA, 2003).

No Amazonas, a produção atual de guaraná concentra-se ainda primordialmente no município de Maués e, em escala bem menor, nos municípios de Urucará, Presidente Figueiredo, Coari e Parintins, conforme a figura 1 .

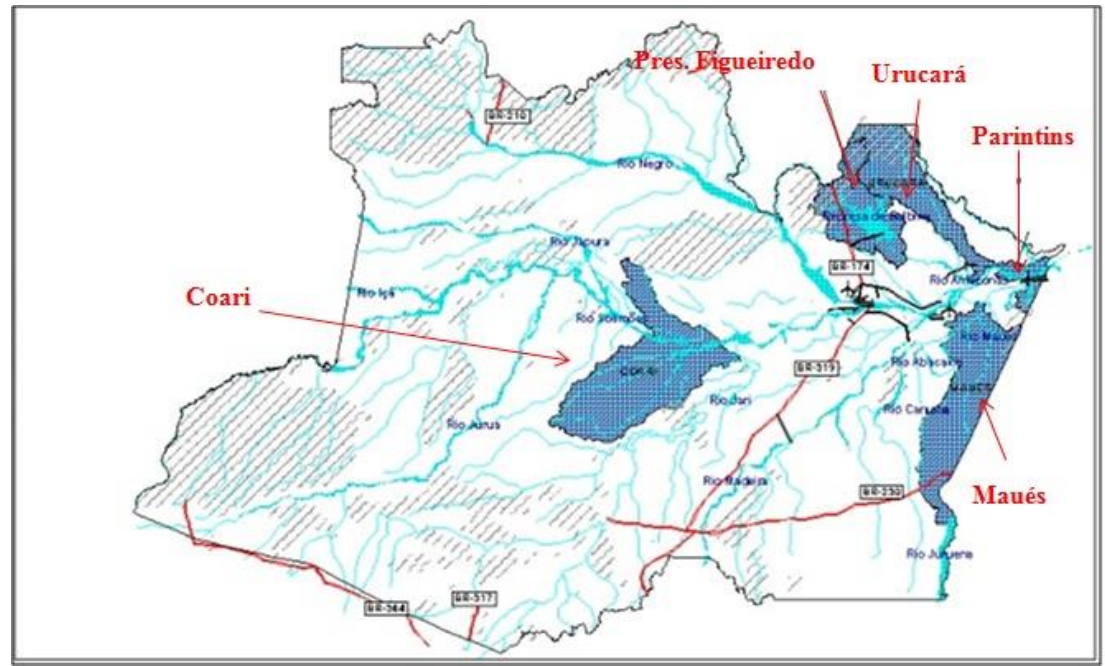

Figura 1 - Municípios do estado do Amazonas que praticam o cultivo do guaraná. Fonte: Adaptado de SUFRAMA (2003). 


\section{METODOLOGIA}

\subsection{Caracterização da pesquisa}

O presente estudo, em termos de abordagem do seu problema, caracteriza-se como uma pesquisa qualitativa por considerar a existência de uma relação dinâmica entre o mundo real e o sujeito, ou seja, um vínculo indissociável entre o mundo objetivo e a subjetividade do sujeito que não pode traduzir-se em números (SILVA \& MENEZES, 2005). A pesquisa qualitativa na análise interpretativa dos dados, depoimentos e falas, busca chegar aos dados não lineares, pois estes possuem uma maior garantia do real e nestes apanham-se a intensidade do fenômeno (DEMO, 2009). Com relação aos objetivos, este trabalho caracteriza-se como uma pesquisa descritiva, pois tem como objetivo descrever as características de determinada população ou fenômeno ou estabelecimento de relações entre variáveis, no caso a empresa Ômega.

O procedimento metodológico utilizado foi o estudo de caso que examina um fenômeno em seu conjunto natural, empregando múltiplos métodos de coleta de dados para coletar informações de uma ou de poucas entidades, tais como pessoas, grupos ou organizações (BENBASAT et al., 1987). Diferente dos estudos racionalistas tradicionais que trabalham com inferências representacionais ou generalidades estatísticas (MEREDITH, 1998; YIN, 1994), o estudo de caso funciona a partir de inferências relacionais ou generalidade analítica (MEREDITH, 1998; YIN, 1994), na busca por generalizar os resultados de um estudo para se criar uma teoria, além da tentativa de determinar se um fator está relacionado a outro.

O estudo de caso permite (GIL, 2002):

1. Explorar situações da vida real cujos limites não estão claramente definidos;

2. Preservar o caráter unitário do objeto estudado;

3. Descrever a situação do contexto em que está sendo feita determinada investigação;

4. Formular hipóteses ou desenvolver teorias; e

5. Explicar variáveis causais de determinado fenômeno em situações muito complexas que não possibilitam a utilização de levantamentos e experimentos. 


\subsection{Caracterização da empresa estudada}

A empresa Ômega é uma pequena empresa industrial especializada na reciclagem de papel e fabricação de telas de fibras vegetal, incluindo as de juta, descobertas e desenvolvidas a partir de pesquisas científicas e de inovação realizadas com o apoio e em parceria com entidades reconhecidas no estado do Amazonas.

Com sede em Manaus, a empresa mantém uma infraestrutura que está localizada em duas áreas: (1) no Centro de Incubação e Desenvolvimento Empresarial (CIDE) para pesquisa e desenvolvimento de protótipos e (2) no Distrito de Micro e Pequenas Empresas (DIMPE) para reciclagem, fabricação de toda a sua linha de produtos e expansão das novas linhas.

A empresa existe desde 2007 e busca a inovação constante por meio da transformação de fibras de juta e outros insumos amazônicos em produtos que sejam ecologicamente corretos. Dentre seus potenciais consumidores estão:

1. Profissionais liberais com bom nível de consciência ambiental;

2. Empresas privadas (varejistas do ramo de papelaria e áreas afins);

3. Órgãos e empresas públicas (promotoras de eventos sobre meio ambiente e áreas afins);

4. Empresas privadas (prestadores de serviços do ramo de turismo ecológico, eventos e áreas afins);

5. Empresas privadas do Polo Industrial de Manaus - PIM (contam como requisito para certificações de excelência o consumo de produtos que não agridam o meio ambiente).

O principal incentivo para a inovação originou-se em seus clientes que incentivaram a empresa a utilizar fibras de juta e outros insumos amazônicos que se tornaram a base para seus produtos. Atualmente, a Ômega utiliza as fibras de juta e malva, como matéria-prima básica, que oferecem a possibilidade de confecção de uma grande variedade de produtos, entre os quais se destacam as sacolas ecológicas (figura 2):

Revista de Administração e Inovação, São Paulo, v.12, n.1, p.121-147, jan./mar. 2015. 


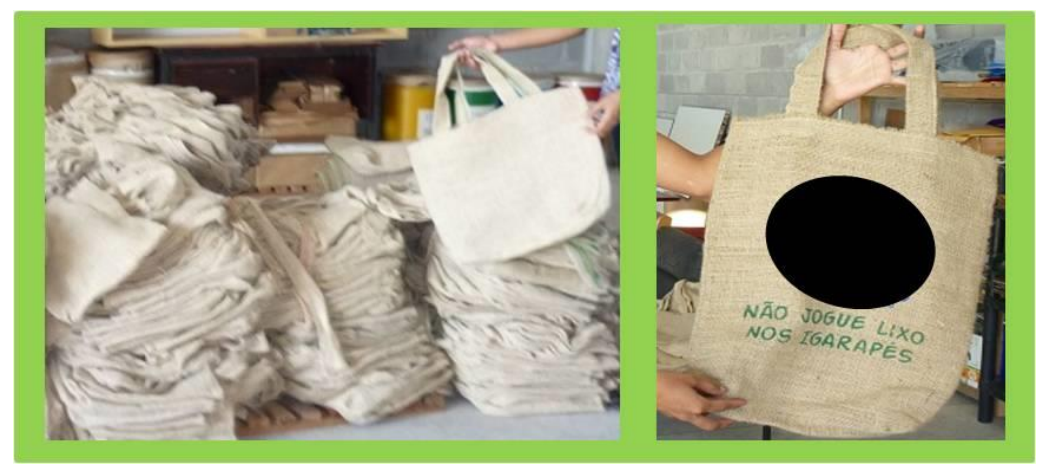

Figura 2: Sacolas ecológicas.

Fonte: Empresa Ômega

\subsection{Métodos de coleta de dados}

A delimitação do universo ocorreu pelo critério de acessibilidade em uma pequena empresa industrial situada na cidade de Manaus, cuja atividade principal está relacionada à reciclagem de papel e fabricação de telas de fibras vegetal, incluindo as de juta. A amostragem pesquisada foi de caráter não probabilística intencional e como técnicas de pesquisa foram utilizadas, segundo classificação de Marconi (1990): (1) a documentação indireta (pesquisa documental e bibliográfica); (2) a observação direta intensiva (observação in loco e entrevista estruturada aberta); e (3) observação direta extensiva (aplicação de formulário).

O estudo foi realizado em quatro momentos: (1) aconteceram duas entrevistas estruturadas abertas (VERGARA, 2009) a partir de um roteiro, baseado em Guérin et al. (2001), onde se identificaram informações fundamentais para o complemento dos formulários aplicados na empresa, posteriormente; (2) ocorreu a pesquisa documental tendo em vista a coleta de dados preliminares em documentos escritos (jornais, revistas e demais publicações externas e internas da empresa) e a observação estruturada (VERGARA, 2009); ocorreu a (3) aplicação do formulário com o proprietário (posterior a observação e as entrevistas); concluindo, (4) realizou-se a análise e a tabulação dos dados quantitativos e qualitativos .

As entrevistas ocorreram de forma aberta, com proprietário e o gerente de produção, partindo da explicação do objeto de estudo; após a breve introdução; os entrevistados iniciaram dando informações do processo de constituição das empresas, historicamente, e em seguida tratou-se das questões da pesquisa, especificamente. As entrevistas seguiram um roteiro que tinha como objetivo identificar questões relacionadas ao funcionamento geral da empresa e a população de trabalho. Os entrevistados não permitiram a gravação, ficando somente a anotação. A duração das entrevistas ficou

Revista de Administração e Inovação, São Paulo, v.12, n.1, p.121-147, jan./mar. 2015. 
entre 70 minutos e 90 minutos. Na pesquisa documental foram apresentados pelo proprietário documentos relacionados à produção e publicações acerca da empresa (jornais, revistas, sites) em mídias locais.

A observação estruturada partiu da metodologia de Guérin et al. (2001), que trata da observação global de uma empresa, na qual a partir da entrevista individual o observador realiza uma breve análise das tarefas e do processo com foco especial na área produtiva. Foram considerados como observáveis gestos, posturas, ações e comunicações entre os funcionários, além de comunicações entre as áreas (produção e administração).

\subsection{Métodos de análise de dados}

Os dados qualitativos obtidos das respostas do roteiro foram tabulados em quadro-resumo, agrupadas conforme o conteúdo e estratificado segundo a estrutura do formulário de ecoinovação. As informações documentais levantadas no segundo momento foram integradas e trianguladas com as informações coletadas pelas entrevistas com o objetivo de garantir a racionalização e a validação construída.

Por fim, os dados do formulário de ecoinovação foram tratados de forma que permitisse uma adequada visualização por meio do gráfico de aranha (spyder chart) e possibilitasse uma adequada caracterização da empresa por meio das análises.

O objetivo do formulário de ecoinovação foi de avaliar o estado atual da empresa com relação ao tema, para isso foi estruturado em três dimensões: (1) entrada das ecoinovações, (2) tarefas técnicas e (3) saída das ecoinovações. A dimensão entrada das ecoinovações busca determinar os elementos primordiais para o desenvolvimento de um ambiente propício às inovações; seccionada em quatro variáveis: (1) especialista para questões ambientais; (2) programas de treinamento e desenvolvimento; (3) capacidade para ecoinovações; e (4) P\&D para questões ambientais.

A dimensão tarefas técnicas foca em aspectos chaves de ações e/ou atividades essenciais na execução das atividades inovativas; estruturada em cinco variáveis: (1) tecnologia de produção; (2) ações técnicas; (3) normatização e sistemas de gestão ambiental; (4) tecnologias utilizadas; e (5) projetos de novos produtos ou processos. Concluindo, a dimensão saída das ecoinovações aponta para os resultados concretos das inovações implantadas pela organização; organizada em três variáveis: (1) introdução de inovações em produtos (bens ou serviços) e processos; (2) inovações organizacionais e de marketing; e (3) resultados e benefícios da introdução das inovações em produtos e processos.

Revista de Administração e Inovação, São Paulo, v.12, n.1, p.121-147, jan./mar. 2015. 
No total são 12 variáveis que se desdobram em 19 perguntas. Logo, o formulário de ecoinovação considera o fluxo padrão de processos (com entrada, transformação/tarefa e saída) voltado para uma melhor visualização e avaliação das atividades relacionadas a essas atividades dentro da empresa.

O formulário adaptado e aplicado na empresa para apoio à avaliação das práticas de ecoinovação baseou-se no apresentado por Arundel \& Kemp (2009) e utilizado no módulo de ecoinovação aplicado no Community Innovation Survey (CIS) da união europeia; nas questões apresentadas em Horbach \& Rennings (2007) e Götzfried (2006); e no formulário utilizado pela ABDI (2012). O processo de tradução e adaptação envolveu quatro etapas: (1) tradução para a língua portuguesa enfatizando a tradução conceitual e não a estritamente literária; (2) retradução para a língua inglesa pelo autor (com conhecimento da língua inglesa); (3) correção e adaptação semântica; e (4) validação do conteúdo por profissional da área (com proficiência na língua inglesa). O Quadro 1 apresenta o detalhamento do formulário por dimensões, variáveis, número de questões e autores.

\begin{tabular}{|c|c|c|c|}
\hline Dimensão & Variável & $\begin{array}{l}\text { Número de } \\
\text { questões }\end{array}$ & Autores \\
\hline \multirow{4}{*}{$\begin{array}{l}\text { Entrada das } \\
\text { ecoinovações }\end{array}$} & Especialistas para questões ambientais & 1 & \multirow{3}{*}{$\begin{array}{l}\text { Adaptado de Arundel \& } \\
\text { Kemp (2009) }\end{array}$} \\
\hline & $\begin{array}{l}\text { Programas de treinamento e } \\
\text { desenvolvimento }\end{array}$ & 1 & \\
\hline & Capacidade para ecoinovações & 1 & \\
\hline & $\mathrm{P} \& \mathrm{D}$ para questões ambientais & 1 & $\begin{array}{l}\text { Adaptado de Horbach \& } \\
\text { Rennings (2007) }\end{array}$ \\
\hline \multirow{5}{*}{ Tarefas Técnicas } & Tecnologia de produção & 1 & \multirow{3}{*}{$\begin{array}{l}\text { Adaptado de Horbach \& } \\
\text { Rennings (2007) }\end{array}$} \\
\hline & Ações técnicas & 1 & \\
\hline & $\begin{array}{l}\text { Normatização e sistemas de gestão } \\
\text { ambiental }\end{array}$ & 1 & \\
\hline & Tecnologias utilizadas & 1 & Adaptado de ABDI (2012) \\
\hline & Projetos de novos produtos ou processos & 1 & Adaptado de ABDI (2012) \\
\hline $\begin{array}{l}\text { Saída das } \\
\text { ecoinovações }\end{array}$ & $\begin{array}{l}\text { Introdução de inovações em produtos } \\
\text { (bens ou serviços) e processos }\end{array}$ & 5 & $\begin{array}{l}\text { Adaptado de Arundel \& } \\
\text { Kemp (2009) }\end{array}$ \\
\hline
\end{tabular}




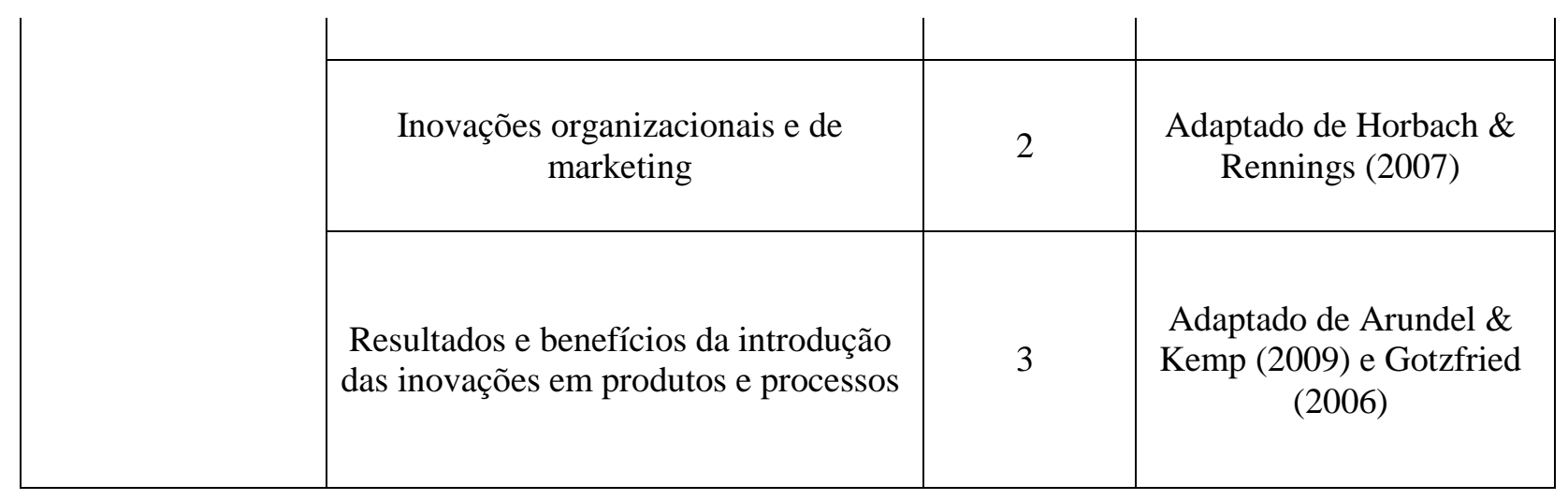

Quadro 1: Dimensões, variáveis, questões e autores utilizados no formuláriode ecoinovação.

Fonte: Elaborado pelo autor.

\section{A EMPRESA ÔMEGA}

Nesta seção será analisado cada um dos critérios que foram avaliados no estudo, apresentando as principais atividades desenvolvidas na organização. Para uma melhor compreensão das ecoinovações da empresa estudada os critérios serão apresentados da seguinte maneira: (1) as ecoinovações; (2) as fontes de inovações e perspectivas futuras; e os (3) resultados das questões de ecoinovação

\subsection{As ecoinovações}

O primeiro produto ecoinovador da empresa Ômega foi a sacola ecológica, com fibras de juta, que possuem sua funcionalidade similar às sacolas de plásticos, contudo diferem na vantagem de serem feitas de material não poluente, reciclável, com maior durabilidade e com processo de produção respeitando o meio ambiente. Os materiais restantes (figura 3), ou seja, as fibras que sobram no final do processo de fabricação das sacolas de juta são aproveitadas, pois a partir desses insumos básicos a empresa confecciona uma ampla variedade de produtos, que incluem artigos de papelaria, brindes promocionais e institucionais, tais como convites, cartões, pastas, bolsas e embalagens (figura 4). 


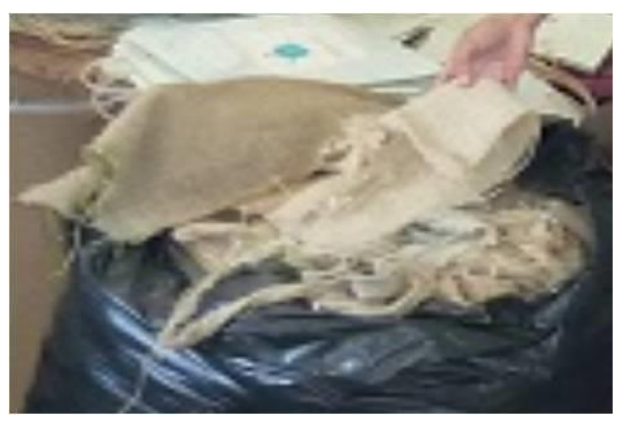

Figura 3: Sobras de fibras de juta. Fonte: Empresa Ômega.

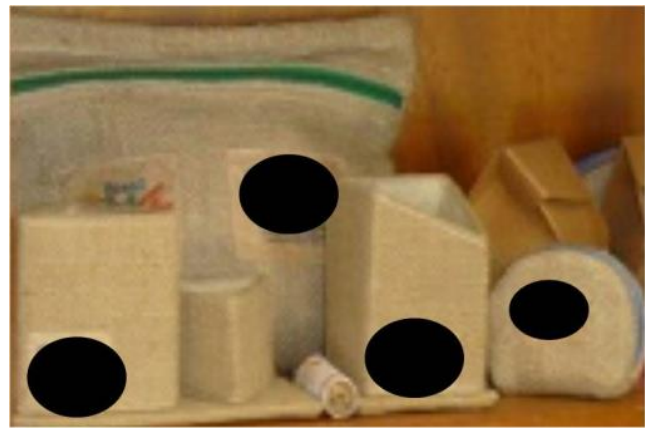

Figura 4: Produtos feitos a partir das sobras de fibras de juta. Fonte: Empresa Ômega

Atualmente, a empresa conta com uma rede de supermercados da capital amazonense como principal comprador das sacolas ecológicas, além da Agência de Desenvolvimento Sustentável do Amazonas (ADS), que solicita os produtos feitos a partir das fibras de juta para utilizá-los em eventos locais, regionais e nacionais. O acompanhamento das vendas para esses e outros clientes está sendo realizado com o intuito de verificar a reação do mercado quanto à aceitação das sacolas de fibras de juta. Existe a pretensão de atingir o mercado consumidor da área que abrange a região amazônica legal e, principalmente, para exportação.

Em consequência das dificuldades com mão de obra interna, a empresa acabou recorrendo a ateliês e costureiras externas que provocaram atrasos na produção. Mediante essa situação, uma segunda ecoinovação adotada, possibilitou o aproveitamento da mão de obra de internos para o trabalho sustentável mediante parceria com a Secretaria de Estado de Justiça e Direitos Humanos do Amazonas (SEJUS/AM). Essa parceria resultou na instalação de um posto de trabalho no COMPAJ (complexo penitenciário) contando inicialmente com 11 internos atuando nas dependências do presídio e com uma entrega inicial de 1,2 mil bolsas para uma grande rede de supermercado de Manaus. Em 2013, a linha de produção passou a contar com 73 internos trabalhando nas sacolas de fibras de juta os quais passaram por uma capacitação na área. 
Do ponto de vista do grau de novidade, essa ecoinovação pode ser considerada nova para a empresa, pois esse tipo de prática apesar de já ter sido adotada em outras empresas e esferas (pública e privada) caracteriza-se como uma nova prática no ambiente interno da empresa.

Uma terceira ecoinovação de destaque foi o desenvolvimento de um papel reciclado formado por 30\% de resíduo do guaraná e seu pigmento, denominado de "papel de guaraná". Nesse caso, o material reaproveitado é a casca do guaraná no qual 100\% dos seus resíduos são utilizados em seus processos produtivos (casca e casquilho) e, com isso, deixam de ser descartados no ambiente. A captação dos resíduos é realizada por meio de uma empresa que possui parceria com as comunidades ribeirinhas e associações indígenas do município de Maués.

A partir de técnicas desenvolvidas durante a pesquisa e desenvolvimento do produto, a casca e o casquilho são processados e transformados em papel. Esse processo inclui a transformação e trituração do casco e casquilho da fruta, a formulação e mistura da polpa de papel, a aplicação de pigmentos naturais, a formação das folhas de papel, prensagem, secagem e a inspeção de qualidade ao final da produção.

Para o processo de design a empresa reúne, em parceria, aproximadamente 25 designers para o desenvolvimento dos novos produtos dos quais se destacam os blocos, as sacolas, os convites e os portfólios, feitos a partir de fibras da bananeira e coqueiro, além de resíduos do abacaxi, malva, juta e açaí. Além do material encadernado, a empresa ainda produz brindes, cachepôs e luminárias de luxo todos feitos à base de papéis artesanais com tingimento de urucum e cascas vegetais variadas, como as da cebola e da banana.

A empresa Ômega menciona que a cooperação, como ocorre em APLs (arranjos produtivos locais), resulta em benefícios para ambas as partes que participam dessa interação. Entre outros tantos benefícios que podem ser enumerados pela empresa e seus parceiros destacam-se:

1. No caso da parceria com o COMPAJ, contribui para o resgate daqueles que vivem no cárcere;

2. Na parceria com a ADS, auxilia na divulgação e conscientização de atitudes em favor do meio ambiente, utilizando as sacolas ecológicas e demais produtos do portfólio da empresa;

3. A parceria com a rede de supermercados local, para que sejam reduzidos os números de sacolas plásticas utilizadas pelo consumidor final;

4. Com o Serviço de Apoio a Micro e Pequena Empresa (SEBRAE) e Serviço Nacional de Aprendizagem Industrial (SENAI), na troca de informações e qualificação da mão de obra;

Revista de Administração e Inovação, São Paulo, v.12, n.1, p.121-147, jan./mar. 2015. 
5. Os fornecedores, para o abastecimento das matérias primas relacionadas tanto à juta quanto ao guaraná. Adequação do maquinário as especificidades das fibras;

6. As universidades e instituições de pesquisa, para o processo de $\mathrm{P} \& \mathrm{D}$ e testes de moldes, textura, personalização e resistência.

Desta forma, vale ressaltar que a empresa desenvolveu uma linha de trabalho de geração de emprego com comunidades, associações, cooperativas e instituições sociais, tais como associação de catadores e associações de mulheres, donas de casa e famílias locais. A divulgação em feiras e telejornais das ações ecológicas e socialmente corretas realizadas pela empresa possibilitou conquistar a credibilidade junto aos fornecedores que antes não tinham uma visão concreta dos negócios, principalmente, do ponto de vista ecológico.

Os fornecedores de fibras de juta e malva que atendem atualmente a empresa Ômega estão sediados no município de Manacapuru e no estado do Pará e os fornecedores de guaraná localizam-se em Maués. Os fornecedores de maquinário, localizados em Manaus, em parceria com a empresa promoveram a adequação das 16 máquinas de corte e de costura dos tecidos às especificidades das fibras de juta.

Além da ecoinovação da empresa Ômega relacionada às fibras de juta e ao guaraná, a empresa realizou incrementos nos produtos, tais como (1) a utilização de tintas que aderissem e ficassem mais bem adequadas ao tecido da juta, resultando no aumento da resistência, maleabilidade e em uma textura mais lisa do tecido; e a (2) personalização dos produtos para cada tipo de cliente ou evento que a empresa participa.

\subsection{Fontes de inovações e perspectivas futuras}

As fontes para as inovações atuais e futuras da empresa baseiam-se em informações oriundas da atividade de pesquisa e do desenvolvimento junto aos fornecedores das fibras de juta e do guaraná, de consultorias especializadas e da cooperação com instituições de pesquisa do Amazonas (INPA e UFAM); a pesquisa em publicações especializadas como revistas sobre micro e pequenas empresas e pesquisa de opinião junto aos clientes complementam as fontes de informações, ou seja, os fornecedores, as universidades e os clientes são as principais fontes de inovação para a empresa.

Entre os novos produtos no mercado (lançado no início de 2013), destacam-se as "persianas ecológicas" confeccionadas com fibras da Amazônia. A persiana evita fungos e possui uma impermeabilização com cera de carnaúba; além das fibras mencionadas, a persiana é composta de

Revista de Administração e Inovação, São Paulo, v.12, n.1, p.121-147, jan./mar. 2015. 
puxadores de fibra de tucum (palmeira de grande porte) e adornados com sementes nativas da Amazônia. Com essa iniciativa, a empresa pretende aumentar a competitividade das fibras naturais diante dos derivados de petróleo. As fibras utilizadas são produzidas a partir das bainhas foliares extraídas do tronco da bananeira e do coco que, uma vez processados, produzem fibras longas e curtas, de cores brancas e marrons.

Entre os objetivos de investimentos para os próximos anos, destacam-se: (1) melhorar a qualidade dos produtos realizando incrementos como bordados, tintas e outros atrativos para as sacolas de juta; (2) planejamento e pesquisa de inovação para novos produtos (persiana ecológica, por exemplo) e (3) continuidade da parceria com o COMPAJ para utilização da mão de obra dos internos. A maior parte dos investimentos atuais e futuros em P\&D da empresa são resultantes da participação no Programa de Apoio à Pesquisa na Pequena Empresa (PAPPE).

Em síntese, constata-se que a empresa Ômega possui como foco atual o desenvolvimento de produtos à base de insumos amazônicos como fonte essencial para a manutenção da competitividade. Vale salientar a preocupação da proprietária com a qualidade da matéria-prima, da mão de obra e das inovações constantes em seus produtos, bem como com estratégias de comercialização e capacidade de atendimento rápida aos pedidos. No caso da comercialização, ocorre basicamente sob encomenda.

\subsection{Resultados do formulário de ecoinovação}

Neste tópico serão apresentados os resultados do formulário aplicado na empresa Ômega relacionado às questões de ecoinovação.

$\mathrm{Na}$ dimensão entrada das ecoinovações, que trata dos insumos necessários para o desenvolvimento de inovações ecológicas, a empresa Ômega não emprega pessoal voltado exclusivamente para atividades inovativas nem tão pouco estabelece programas de treinamento e desenvolvimento para os funcionários. Essa informação é um reflexo das dificuldades que as MPEs brasileiras enfrentam para o desenvolvimento de atividades inovativas.

Como pontos positivos, observa-se que a empresa reserva tempo para implementação de novos produtos e processos ecológicos. Esse processo ocorre fundamentalmente por meio das parcerias com instituições de pesquisa locais. Somada a essa situação, a empresa mencionou que destina aproximadamente $15 \%$ de seu orçamento total para as atividades de P\&D.

$\mathrm{Na}$ dimensão tarefas técnicas, que trata do processo de transformação envolvendo as atividades ecoinovadoras no que tange à variável tecnologia de produção e ambiental, a empresa informou que as modificações significativas relacionadas às tecnologias de produção envolveram 
mudanças do tipo tecnologias de fim de tubo que permitiram a recuperação dos recursos utilizados, tais como as sobras da fabricação de sacolas utilizadas para a produção de produtos de papelaria.

No caso das tecnologias fim de tubo, conforme estudo de Oltra et al. (2009) essas tecnologias representam boa parte das eco-patentes. Outro estudo de Barbosa (2011), aponta que as ecoinovações de fim de tubo foram a segunda principal fonte de eco-patentes na Unicamp entre 1989 e 2007. Conforme mencionado na revisão da literatura, essa tecnologia possui relevância por ser altamente patenteável devido principal a temática dos impactos ambientais e por serem facilmente identificáveis.

No concernente à variável ações técnicas, entre as modificações significativas realizadas pela empresa relacionadas às características da natureza dos produtos/processos, destacam-se as mudanças na distinção dos produtos, ou seja, produtos tradicionais como as sacolas plásticas, papel e as persianas que passaram a ser produzidos com matéria prima amazônica.

Na variável normatização e sistemas de gestão ambiental, a empresa não implementou nenhum sistema de gestão ambiental nos últimos três anos, refletindo uma postura ainda comum das MPEs de imaginarem que normas específicas, como da família ISO, acabam sendo úteis apenas para as médias e grandes empresas.

A variável tecnologias utilizadas evidencia que dentro dos processos internos da empresa Ômega acontece a predominância da utilização de tecnologias voltadas para a reciclagem/reaproveitamento e para o eco-design resultantes do foco da empresa no desenvolvimento de produtos à base de insumos amazônicos reaproveitáveis (beneficiamento da juta, malva e guaraná). A empresa não utiliza tecnologias destinadas ao tratamento da água, do ar, do solo e da gestão da água. Observa-se uma relação entre a tecnologia utilizada e os projetos de desenvolvimento de produtos e processos.

Entre os projetos de novos produtos e processos, a empresa destacou que estão desenvolvendo projetos em novos produtos e processos na mesma linha da variável anterior, tecnologias para reciclagem/reaproveitamento e eco-design. De forma análoga à variável anterior, a empresa não está desenvolvendo produtos ou processos destinados ao tratamento da água, do ar, do solo e da gestão da água.

A dimensão saída das ecoinovações diz respeito aos resultados finais, bem como os benefícios alcançados por meio das ecoinovações. Na variável introdução de inovações em produtos (bens ou serviços) e processos, os principais motivos pelos quais a empresa estudada introduziu inovações no mercado foi em atendimento à disponibilidade de subsídios governamentais, no caso o PAPPE e atendimento à demanda de mercados atuais ou esperada por seus clientes para o tema. Na realidade, a 
empresa caminha em direção da utilização de matérias primas alternativas em consonância com as questões ambientais que permeiam a sociedade atual.

No entanto, a empresa não possui instrumentos adequados para a identificação, o mapeamento e a redução dos seus impactos ambientais. A empresa necessita desenvolver mecanismos formais para identificação de demandas ecológicas e redução dos impactos ambientais. Conforme as ecoinovações apresentadas anteriormente e de acordo com as respostas do formulário, nos últimos anos a empresa introduziu inovações a partir de programas de reciclagem, produtos aperfeiçoados e mais ecológicos, em comparação aos concorrentes do mercado, e processos aperfeiçoados com benefícios ambientais, tais como a utilização de tintas mais adequadas ao tecido da juta. A predominância das inovações apontadas pela empresa no formulário e verificados na observação direta são de inovações em produtos sem relação com a existência ou antecipação a medidas de políticas ambientais.

$\mathrm{Na}$ variável inovações organizacionais e de marketing, somente ocorreu a informação aos consumidores das formas utilizadas pela empresa para a redução dos impactos ambientais. Na variável práticas estabelecidas para determinar a implementação da gestão ambiental, nenhuma das práticas mencionadas no formulário foram desenvolvidas pela empresa.

Entre os resultados mencionados da introdução de novos produtos e processos, a organização destacou como os critérios com maior relevância para os objetivos dos produtos e processos: o maior alcance dos bens e serviços; a entrada em novos mercados ou aumento do market share; e a melhoria da qualidade de bens e serviços. Todos receberam como grau de importância elevado, evidenciando a importância que a empresa destina aos seus produtos ecoinovadores. O gráfico 1 apresenta a importância para os objetivos de produtos e processos apontados pela empresa.

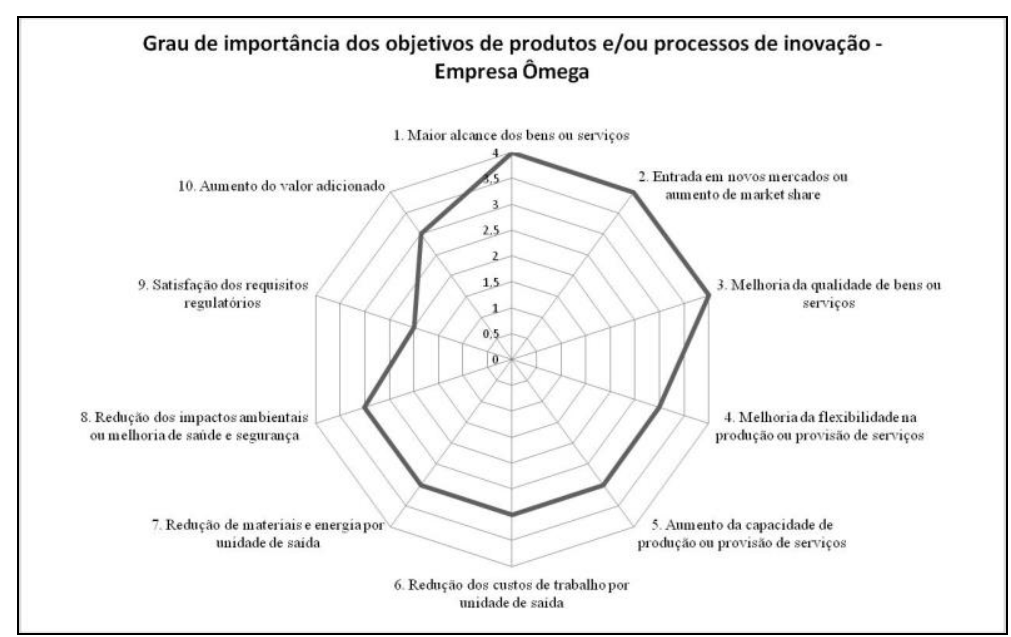

Gráfico 1: Grau de importância dos objetivos de produtos e/ou processos de inovação - Empresa Ômega.

Fonte: Elaborado pelo autor. 
Entre os benefícios ambientais da produção de bens ou serviços foram assinalados positivamente (1) a substituição de materiais por outros insumos menos poluidores, tais como a utilização dos resíduos do guaraná e da fibra de juta e malva; e (2) um segundo benefício assinalado trata da utilização de resíduos reciclados por meio do desenvolvimento das sacolas ecológicas.

Por fim, o último aspecto positivo apresentado nessa dimensão trata dos benefícios dos resíduos reciclados e materiais, especialmente o guaraná e as sobras da fabricação das sacolas ecológicas. Quanto aos benefícios ambientais após as vendas dos bens pelo usuário final a empresa mencionou que não houve retornos significativos com relação aos três critérios apontados no formulário.

\subsection{Discussão}

No que tange às inovações, a empresa realizou seu processo de inovação por meio da transformação de insumos amazônicos em produtos ecologicamente corretos e inovadores, destacandose (1) as sacolas ecológicas e o (2) papel de guaraná. Entre as atividades inovativas em produtos em destaque tem-se: a inovação pela utilização da fibra da juta para confecção de sacolas ecológicas, a utilização do papel de guaraná utilizando resíduos da casca do guaraná e a reutilização das sobras da produção para confecção de novos produtos, tais como, convites, cartões, pastas, bolsas e embalagens.

Aconteceram, ainda, inovações incrementais nos produtos resultantes de pesquisas para a utilização de tintas que ajustem melhor ao tecido da juta. Por conseguinte, observam-se inovações nos processos pela readequação das máquinas, junto com o fornecedor de maquinários, para os fios da juta. Ressalta-se no estudo a importância das parcerias com as instituições de ensino e pesquisa locais foram fundamentais para as diversas etapas do processo de P\&D. O Quadro 2 sintetiza as principais inovações identificadas no estudo, sua classifica segundo o tipo e a novidade da inovação implementada.

\begin{tabular}{|c|c|c|}
\hline Inovações & Tipo de inovação & $\begin{array}{c}\text { Novidade da } \\
\text { inovação }\end{array}$ \\
\hline Sacolas ecológicas com fibra da juta & Produto & Novo para empresa \\
\hline Papel de guaraná & Produto & $\begin{array}{c}\text { Novo para o } \\
\text { mercado }\end{array}$ \\
\hline $\begin{array}{c}\text { Reutilização das sobras para confecção } \\
\text { de novos produtos }\end{array}$ & Processo & Novo para empresa \\
\hline
\end{tabular}




\begin{tabular}{|c|c|c|}
$\begin{array}{c}\text { Readequação das tintas e máquinas aos } \\
\text { fios da juta }\end{array}$ & Processo & Novo para empresa \\
\hline $\begin{array}{c}\text { Design para o desenvolvimento de novos } \\
\text { produtos }\end{array}$ & Processo & Novo para empresa \\
\hline Cooperação interinstitucional & Organizacional & Novo para empresa \\
\hline Utilização de mão de obra penitenciária & Social & Novo para empresa \\
\hline $\begin{array}{c}\text { Persianas ecológicas com insumos } \\
\text { amazônicos }\end{array}$ & Produto & $\begin{array}{c}\text { Novo para o } \\
\text { mercado }\end{array}$ \\
\hline
\end{tabular}

Quadro 2: Inovações, tipo de inovação e a novidade da inovação implementada Empresa Ômega.

Fonte: Elaborado pelo autor.

O Quadro 1 corrobora os resultados das cinco edições da PINTEC que apontam para um grau de novidade limitado para a própria empresa (especialmente nas micro e pequenas). As empresas brasileiras possuem forte tendência às inovações incrementais e esse estudo evidencia essa situação (no caso das tecnologias de fim de tubo), todavia a academia e as empresas precisam considerar que o processo de inovação é cumulativo (PAVITT, 1984) e a aquisição de tecnologias por essas empresas, hoje, podem resultar em um desenvolvimento tecnológico próprio em médio e longo prazo.

Por meio do formulário de ecoinovação, observou-se como ponto forte na dimensão "Entrada das ecoinovações" o dispêndio de tempo e recursos da empresa para atividades de P\&D. Na dimensão "tarefas técnicas", destaca-se a correlação entre as tecnologias utilizadas e os projetos de novos produtos ou processos. Na dimensão "Saída das ecoinovações", evidencia-se a introdução de novos produtos mais ecológicos em comparação aos existentes no mercado.

Com relação à revisão da literatura, observou-se uma adequação das inovações em produtos e processos desenvolvidos pela empresa Ômega com os conceitos apresentados na revisão. Como principal orientador da inovação na empresa, destaca-se a busca por novos mercados em consonância ao apresentado por Arundel \& Kemp (2009) e observou-se um equilíbrio entre ecoinovações em produtos e processos, conforme mencionado em Bleischwitz et al. (2009). Por fim, seguindo a classificação de Kemp \& Pearson (2008), a empresa Ômega pode ser considerada como ecoinovadora estratégica. Em resumo, o estudo possibilitou um diálogo entre as atividades que são consideradas ecoinovadoras pela literatura e as práticas desenvolvidas pela empresa.

A metodologia adotada permitiu uma melhor compreensão das atividades inovadoras realizadas na empresa por meio da aplicação de um formulário de ecoinovação, da realização de entrevistas estruturadas abertas e de observações estruturadas na empresa. 


\section{CONSIDERAÇÕES FINAIS}

O objetivo deste trabalho consistiu em fazer uma análise para uma visualização do processo de ecoinovação realizado pela empresa Ômega. A adoção do formulário de ecoinovação, das entrevistas e observações foram fundamentais para que o objetivo fosse alcançado.

Entre os principais resultados alcançados pelo estudo, destaca-se explicitar as inovações em produtos a base de insumos amazônicos, em processo a partir da readequação de máquinas devido a especificidade da matéria prima adota e inovação social com a adoção de uma prática nova para a empresa a qual utiliza mão de obra carcerária. A adequação entre as inovações em produtos e processos desenvolvidos pela empresa e a literatura apresentada pode ser considerado como resultado adicional.

Os resultados do formulário de ecoinovação possibilitaram a organização repensar suas futuras estratégias de produtos e processos (organizacional, marketing, social) ecoinovadores, tendo como base as três dimensões utilizadas no estudo e comparando o seu estado atual com uma posição futura desejável. Adicionalmente, o formulário poderá ser utilizado em surveys voltados ao tema ou relacionados a atividades de inovação como a Pesquisa de Inovação Tecnológica (PINTEC), por exemplo.

Como limitações do estudo, aponta-se para a amostra da pesquisa ter se tratado de apenas uma empresa e, consequentemente, como sugestões para pesquisas futuras, indica-se a aplicação do formulário em uma amostra maior e de atividades econômicas distintas. No que tange o formulário de ecoinovação, a retradução ou o retorno ao idioma original (back-translation) foi realizado pelo próprio autor podendo ser considerada uma limitação do método de pesquisa.

Portanto, a empresa Ômega pode ser considera ecoinovadora pela utilização de insumos amazônicos naturais, com técnicas produtivas que promovem a reutilização de matéria prima, com a utilização de mão de obra de internos e promovendo uma nova inclusão social a esses indivíduos. A relevância do estudo reside na validação das ecoinovações desenvolvidas pela empresa e observadas in loco com a literatura existente e pela utilização de um formulário de ecoinovação que poderá ser empregado tanto para avaliação e direcionamento interno quanto para fonte de dados externos. 


\section{REFERÊNCIAS}

ABDI - AGÊNCIA BRASILEIRA PARA O DESENVOLVIMENTO INDUSTRIAL. Sondagem da Inovação da ABDI. $2^{\circ}$ trimestre (abril/ maio/ junho). Brasília: ABDI, 2012.

ARUNDEL, A.; KEMP, R. Measuring eco-innovation. UNU-MERIT Working paper series 2009017. Maastricht: UNU-MERIT, 2009.

BARBIERI, J. C. et al. Inovação e sustentabilidade: novos modelos e proposições. Revista de Administração de Empresas - RAE, v. 50, n. 2, pp. 146-54, abr./jun. 2010.

BARBOSA, R. K. Eco-inovação na universidade: uma análise das patentes da Universidade de Campinas. Campinas: Unicamp, 2011. Dissertação (Mestrado em Desenvolvimento Econômico, Espaço e Meio Ambiente), Instituto de Economia, Universidade de Campinas, 2011.

BENBASAT, I. et al. The case research strategy in studies of information systems. MIS Quarterly, v. 11, n. 03, pp. 369-386, september, 1987.

BENTES, D. S.; ROLIM, A. R. O Amazonas no Brasil e no Mundo. Manaus: Mens'sana, 2005.

BLEISCHWITZ, R. et al. Eco-innovation - putting the EU on the path to a resource and energy efficient economy. Wuppertal spezial 38. Alemanha, 2009.

CASSIOLATO, J. E.; LASTRES, H. Sistemas de Inovação: políticas e perspectivas. Parcerias Estratégicas, n. 08, p. 237-255, 2000.

FRONDEL, M. et al. End-of-pipe or cleaner production? An empirical comparision of environmental innovation decisions across OECD countries. Discussion paper $\mathbf{n}^{\circ}$ 04-82. Alemanha: ZEW, 2004.

FUSSLER, C.; JAMES, P. Driving Eco-innovation: a breakthrough discipline for innovation and sustainability. London: Pitman Publishing, 1996.

GALBRAITH, J. R. Designing the innovation organization. CEO Publication G 99-7 (366). Los Angeles, CA - USA: Center for effective organizations (CEO), 1999. Disponível em: <http://ceo.usc.edu/pdf/G997366.pdf $>$, acesso em: junho de 2012.

GIL, A. C. Como elaborar projetos de pesquisa. 4. ed. São Paulo: Atlas, 2002.

GÖTZFRIED, A. Community innovation statistics - from today's Community Innovation Survey's to better surveys tomorrow. Draft paper, Luxemburg, 2006.

GUÉRIN, F. et al. Compreender o trabalho para transformá-lo: a prática da ergonomia. São Paulo: Blücher: Fundação Vanzolini, 2001.

HOMMA, A. K. O. Os japoneses na Amazônia e sua contribuição ao desenvolvimento agrícola. Revista Somanlu, v. 9, n. 1, pp. 113-33, jan./jun., 2009.

HORBACH, J.; RENNINGS, K. Survey Analysis of Eco-Innovation: Possibilities and Propositions: Deliverable 4 \& 5 of the MEI (Measuring Eco-Innovation Project), UM-MERIT. Maastricht. 2007. 
Ecoinovação em uma pequena empresa de reciclagens da cidade de Manaus

IDAM - INSTITUTO DE DESENVOLVIMENTO AGROPECUÁRIO E FLORESTAL

SUSTENTÁVEL DO AMAZONAS. Juta. Disponível em:

<http://www.idam.am.gov.br/busca.php?busca=juta\&secao=not>. Acesso em: dezembro de 2011.

KEMP, R.; PEARSON, P. Final report MEI project about measuring eco-innovation. UMMERIT. Maastricht. 2008.

MAÇANEIRO, M. B.; CUNHA, S. K. Eco-Inovação: um quadro de referências para pesquisas futuras. In: XXVI Simpósio de Gestão da Inovação Tecnológica. Vitória/ES. Novembro/2010. pp. $1-17$.

MARCONI, M. A. Técnicas de pesquisa: planejamento, e execução de pesquisas (...). 2.ed. São Paulo: Atlas, 1991.

MEREDITH, Jack. Building operations management theory through case and field research. Journal of operations management, v. 16, pp. 441-454, 1998.

OECD - ORGANISATION FOR ECONOMIC CO-OPERATION AND DEVELOPMENT. Better policies to support eco-innovation. OECD studies on environmental innovation. Paris, 2011.

Paris, 2009a.

Sustainable manufacturing and eco-innovation: framework, practices and measurement.

$\ldots$. Sustainable manufacturing and eco-innovation: towards green economy. Policy brief, june 2009b.

Oslo manual: the measurement of scientific and technological activities. 3. ed. 2005. Traduzido pela Finep. Disponível em: http://www.mct.gov.br . Acesso em: junho de 2012.

OLTRA, V. et al. Patents as a measure for eco-innovation. Cahiers du GREThA $\mathbf{n}^{\circ}$ 2009-05. França: Gretha, 2009.

RENNINGS, K. Towards a theory and policy of eco-innovation - neoclassical and (Co-) evolutionary perspectives. ZEW discussion papers 98-24, pp. 1-21, 1998.

SANTOS, J. D. Fibras de juta e malva: proposta de preço mínimo safra 2006/2007. Brasília: Conab, 2007. Disponível em http://www.conab.gov.br/conabweb. Acesso em: janeiro de 2013.

SAWHNEY, M et al. The 12 different ways for companies to innovate. MIT Sloan Management Review, v. 47, n. 3, p. 75-81, 2006.

SILVA, E. L.; MENEZES, E. M. Metodologia da pesquisa e elaboração de dissertação. 4. ed. Florianópolis: UFSC, 2005.

SOUZA, H. H. et al. Sustentabilidade e sociedade: máquina descortiçadora de fibra de Malva (Urena Lobata L.), tecnologia social a serviço dos caboclos ribeirinhos do Amazonas. Grupo de trabalho: Sociedade, trabalho e saberes tradicionais. In: II Encontro da Sociedade Brasileira de Sociologia da Região Norte. 13 a 15 de setembro de 2010. Belém - PA.

SUFRAMA - SUPERINTENDÊNCIA DA ZONA FRANCA DE MANAUS. Guaraná. Manaus: SUFRAMA, 2003.

Revista de Administração e Inovação, São Paulo, v.12, n.1, p.121-147, jan./mar. 2015. 
TIDD, J.; BESSANT, J.; PAVITT, K. Gestão da Inovação. 3.ed. Porto Alegre: Bookman, 2008.

VERGARA, S. C. Métodos de coleta de dados no campo. São Paulo: Atlas, 2009.

VON HIPPEL, E. Sources of innovation. New York: Oxford University Press, 1988.

YIN, Robert K. Case Study Research: Design and Methods. 2. ed. Newbury Park, CA: Sage Publications, 1994.

\title{
ECO-INNOVATION IN A SMALL RECYCLING ENTERPRISE IN THE CITY OF MANAUS
}

\begin{abstract}
This paper aims to characterize an analysis of the process of eco-innovation held by the Omega enterprise. Regarding the methodology this work is considered a qualitative and descriptive research and using the case study as methodological procedure. Research techniques used were the indirect documentation (desk research), the intensive direct observation (observation and structured interview) and extensive direct observation (form of eco-innovation). Results are presented in the context of the enterprise and the production process, the results of the form of eco-innovation and the main ecoinnovations (product, process and social) adopted by the company. The conclusions point to the adequacy of the innovations in products and processes developed by the enterprise and literature presented with this, the Omega enterprise can be considered as eco-inovator strategic. The relevance of this study lies in presenting a form to evaluate ecoinovadoras activities within enterprises and validating between eco-innovations observed in the firm and literature.
\end{abstract}

Keywords: Innovation; Eco-innovation; Jute fibre; Guaraná; Amazonas.

Data do recebimento do artigo: 05/03/2014

Data do aceite de publicação: 15/04/2015

Revista de Administração e Inovação, São Paulo, v.12, n.1, p.121-147, jan./mar. 2015. 